\title{
Kinetic Study on Iso-concentration Hydrogen Peroxide Bleaching of Poplar Chemi-thermomechanical Pulp by the Process of Continuous Chemical Supplement
}

\begin{abstract}
Xianqi Sun, ${ }^{\mathrm{a}, \mathrm{c}}$ Qingxi Hou, ${ }^{\mathrm{a}, *}$ Haizhen Shi, ${ }^{\mathrm{b}}$ and Lichun Zhou ${ }^{\mathrm{c}}$
In the authors' previous studies, a bleaching process based on continuous chemical supplementation (CCS) was proposed to improve the effectiveness of peroxide bleaching of chemi-thermomechanical pulp (CTMP). In this study, the kinetic model of the CCS process of peroxide bleaching was applied to poplar CTMP to explore how the bleaching rate was affected. The model was based on the rate of chromophore elimination characterized by the brightness gains of bleached pulp. The reaction rate of chromophore destruction proceeded via a rapid initial phase followed by a slow phase. The equation of reaction rate was confirmed. The value of reaction order was -3.62 , and the activation energy was $288.8 \mathrm{~kJ} / \mathrm{mol}$. The developed kinetic model was a good fit for the experimental results.
\end{abstract}

Keywords: Continuous chemical supplement (CCS); Kinetics; Peroxide bleaching; Chemi-thermomechanical pulp (CTMP)

Contact information: a: Tianjin University of Science \& Technology, Tianjin 300457, China; b: Longyou Speciality Paper Research Institute, Longyou 324400, Zhejiang Province, China; c: China National Pulp and Paper Research Institute, Beijing 100102, China;

* Corresponding author: qingxihou@tust.edu.cn

\section{INTRODUCTION}

Bleached chemi-mechanical pulp (CTMP) is an important fiber stock in the paper industry due to several advantages over chemical pulp such as lower cost, higher pulping yield, higher opacity, and higher bulk. It is commonly used in many types of paper products including light-weight printing paper, supercalendered (SC) paper, and white cardboard (Sundholm 1999). The CTMP is mostly bleached by using hydrogen peroxide, which has advantages of a higher brightening capability, less yellowing after bleaching, and lower pollution load (Ek et al. 2009). However, the bleaching efficiency, which can be defined as the $\Delta \%$ ISO brightness $/ \Delta \% \mathrm{H}_{2} \mathrm{O}_{2}$ consumed with oven-dried pulp, is very low (Xu 2002; Zhao 2009; Zhao et al. 2010). The low bleaching efficiency is mainly attributed to excessive decomposition of hydrogen peroxide, which is caused by undesirable chemical concentrations. In traditional high-consistency peroxide bleaching, the concentration of various chemicals, especially $\mathrm{H}_{2} \mathrm{O}_{2}$ and total alkali, would decline sharply from approximately $20 \mathrm{~g} / \mathrm{L}$ to $5 \mathrm{~g} / \mathrm{L}$ for $\mathrm{H}_{2} \mathrm{O}_{2}$ and $10 \mathrm{~g} \mathrm{NaOH} / \mathrm{L}$ to $0.2 \mathrm{~g} \mathrm{NaOH} / \mathrm{L}$ for the total alkali (Behrooz et al. 2012). The decline of these chemical concentrations are not optimal for achieving a high bleaching efficiency, i.e., the concentrations in the bleaching reaction are too high at the initial phase and are too low at the end phase, resulting in a low bleaching efficiency (Shen 2008; Wang et al. 2008; Zhao 2009).

To improve the unreasonable chemical concentration during the peroxide bleaching process, Sun et al. (2017) proposed the continuous chemical supplementation (CCS) 
peroxide bleaching process. Hydrogen peroxide and sodium hydroxide were continuously replenished to the bleaching system to match their consumption, keeping the concentrations constant during bleaching. Therefore, the undesired decomposition of peroxide was avoided, and the bleaching efficiency significantly increased.

The CCS peroxide bleaching system is quite distinct from the conventional bleaching system. However, at present the kinetic model of the CCS bleaching process has not been made clear. The present study investigates the bleaching kinetics of poplar CTMP in the CCS peroxide bleaching process. The reaction orders, activation energy, and reaction rate constant are given. The objective of this work is to improve the efficiency of the peroxide bleaching for poplar CTMP through a better understanding of the reaction kinetics.

\section{EXPERIMENTAL}

\section{Materials}

Unbleached poplar CTMP samples were received from a pulping mill (Taiding New Materials Co., Ltd., Shandong Province, China). The samples were washed with deionized water, thickened to a consistency of approximately $30 \%$, and stored in a cold room at approximately $4{ }^{\circ} \mathrm{C}$ for later use.

\section{Chemicals}

The chemicals used in the study were sodium silicate ( $41^{\circ}$ Bé) from China PQ Silicates Technology Co., Ltd. (Tianjin, China), stabilizer P (Chunjiang Chemicals Co., Ltd., Changzhou, China), magnesium hydroxide slurry (80 g/L) (Haililong Magnesium Technology Co., Ltd., Weifang, China), and diethylenetriaminepentaacetic acid (DTPA) (Akzo Nobel N.V., Amsterdam, Netherlands). Hydrogen peroxide and sodium hydroxide were purchased from Jiangtian Chemical Co. (Tianjin, China). All of the chemicals used were of analytical grade unless otherwise specified.

\section{Instruments}

The flow chart and related apparatus for the CCS peroxide bleaching process are shown in Fig. 1, in which 1 is the thermostatic bath, 2 is the reactor, 3 is the stirrer, 4 is the peristaltic pump for $\mathrm{H}_{2} \mathrm{O}_{2}, 5$ is the plastic container for $\mathrm{H}_{2} \mathrm{O}_{2}, 6$ is the computer, 7 is the plastic container for $\mathrm{NaOH}$, and 8 is the peristaltic pump for $\mathrm{NaOH}$.

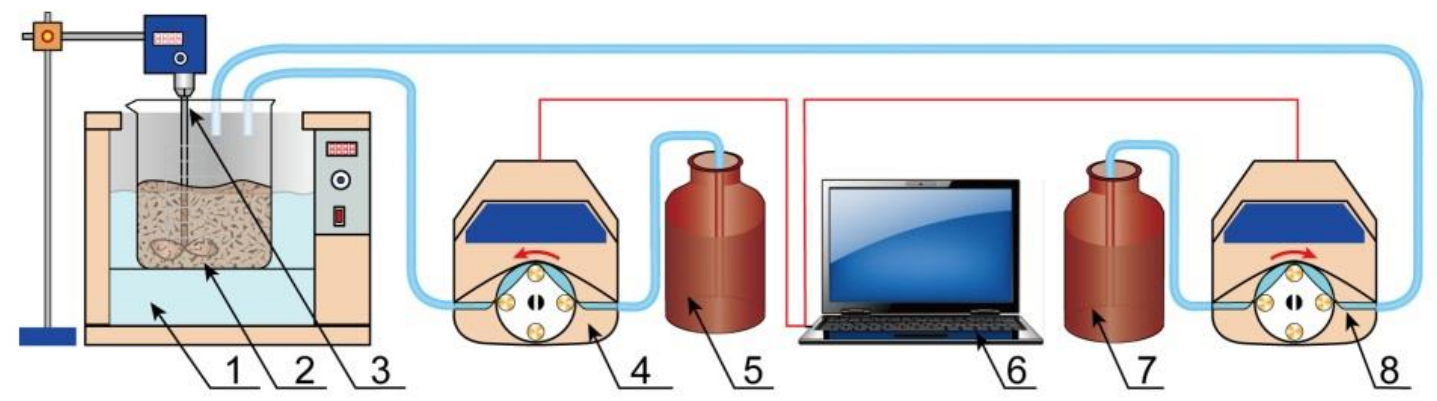

Fig. 1. Flow chart and related apparatus for the CCS peroxide bleaching process 


\section{Peroxide bleaching}

The $40.00 \mathrm{~g}$ of oven-dried unbleached poplar CTMP was placed in the reactor and then diluted with deionized water to a pulp consistency of $5 \%$, followed by mixing at a stirring speed of $200 \mathrm{rpm}$. When the temperature of pulp reached the set value as shown in Table 1, the following bleaching chemicals were added to the pulp: $0.2 \% \mathrm{Mg}(\mathrm{OH})_{2}, 0.3 \%$ stabilizer P, and $0.2 \%$ DTPA with oven-dried unbleached pulp. Subsequently, $\mathrm{Na}_{2} \mathrm{SiO}_{3}$, $\mathrm{NaOH}$, and $\mathrm{H}_{2} \mathrm{O}_{2}$ were successively added to the pulp to reach the initial chemical concentrations in the bleaching system $\left(4.50 \mathrm{~g} / \mathrm{L} \mathrm{H}_{2} \mathrm{O}_{2}, 0.50 \mathrm{~g} / \mathrm{L} \mathrm{NaOH}\right.$, and $2.50 \mathrm{~g} / \mathrm{L}$ $\mathrm{Na}_{2} \mathrm{SiO}_{3}$ ). Finally, the pulp was diluted to a consistency of $4.0 \%$ with deionized water, and the peristaltic pumps began to replenish the consumed peroxide and total alkali by pumping $60 \mathrm{~g} / \mathrm{L} \mathrm{H} \mathrm{O}_{2}$ and $30 \mathrm{~g} / \mathrm{L} \mathrm{NaOH}$ solutions. The initial concentrations of $\mathrm{H}_{2} \mathrm{O}_{2}$ and total alkali in the bleaching system remained constant for the present time in the bleaching process as shown in Table 1. The brightness of the bleached CTMP was measured.

Table 1. Experimental Design

\begin{tabular}{|c|c|c|}
\hline Experimental Run & Temperature $(\mathrm{K})$ & Time $(\mathrm{min})$ \\
\hline 1 & 338.15 & $5,10,20,30,40,50$ \\
\hline 2 & 348.15 & $5,10,20,30,40,50$ \\
\hline 3 & 358.15 & $5,10,20,30,40,50$ \\
\hline 4 & 368.15 & $5,10,20,30,40,50$ \\
\hline 5 & 353.15 & $5,10,20,30,40,50$ \\
\hline
\end{tabular}

\section{Methods}

\section{Experimental procedure}

To determine the constant of the bleaching reaction rate and reaction orders in the proposed bleaching rate equation, a series of bleaching experiments were completed with fixed chemical concentration, pulp consistency, and bleaching reaction temperature, but with various reaction times. The relationship between the brightness gains and the bleaching reaction time was then established, and the best-fit values of the bleaching rate constant $(k)$ and the reaction order variables $(\gamma)$ in the bleaching rate equation were simultaneously calculated. Then, similar experiments were repeated, where the reaction temperatures were varied, but other parameters were fixed. The aformentioned data analysis were also repeated. The activation energy $(\varepsilon)$ was determined according to the Arrhenius equation (Keating et al. 2008; Wang et al. 2008; Liu et al. 2014),

$$
k=A e^{-\frac{\varepsilon}{R T}}
$$

where $k$ is reaction rate constant, $A$ is a pre-exponential factor, $R$ is molar gas constant $(8.314 \mathrm{~J} / \mathrm{mol} \cdot \mathrm{K}), T$ is a thermodynamic temperature $(\mathrm{K})$, and $\varepsilon$ is activation energy $(\mathrm{J} / \mathrm{mol})$.

\section{RESULTS AND DISCUSSION}

\section{Principle of the Method}

The kinetic model of conventional peroxide bleaching has a general expression as shown in Eq. 2 (Chen et al. 1996; Sofia et al. 2007) below,

$$
\mathrm{d} w / \mathrm{d} t=k_{0}\left[\mathrm{H}_{2} \mathrm{O}_{2}\right]^{\alpha}[\mathrm{NaOH}]^{\beta} w^{\gamma}
$$


where $w$ is the brightness gain (\%ISO), $t$ is the bleaching reaction time (min), $k_{0}$ is the reaction rate constant, and $\alpha, \beta$, and $\gamma$ are the orders of bleaching reaction. Because the concentrations of hydrogen peroxide and total alkali are constant in the CCS bleaching process (Sun et al. 2017), Eq. 2 can be simplified into Eq. 3:

$$
\mathrm{d} w / \mathrm{d} t=k w^{\gamma}
$$

Therefore, the relationship between the constant $(k)$ of the bleaching reaction rate and reaction temperature $(T)$ can be expressed by using Eq. 1.

\section{Confirmation of the Bleaching Reaction Order $(y)$}

Similar to the conventional peroxide bleaching process (Xu and Hoddenhagh 2003), the CCS bleaching process can be described by a rapid reaction phase initially followed by a considerably slower reaction phase. However, the brightness development in the CCS bleaching process was steadily maintained, unlike the conventional peroxide bleaching process. This was due to the even reaction rate that was maintained by continuous chemical supplement in the CCS bleaching process.

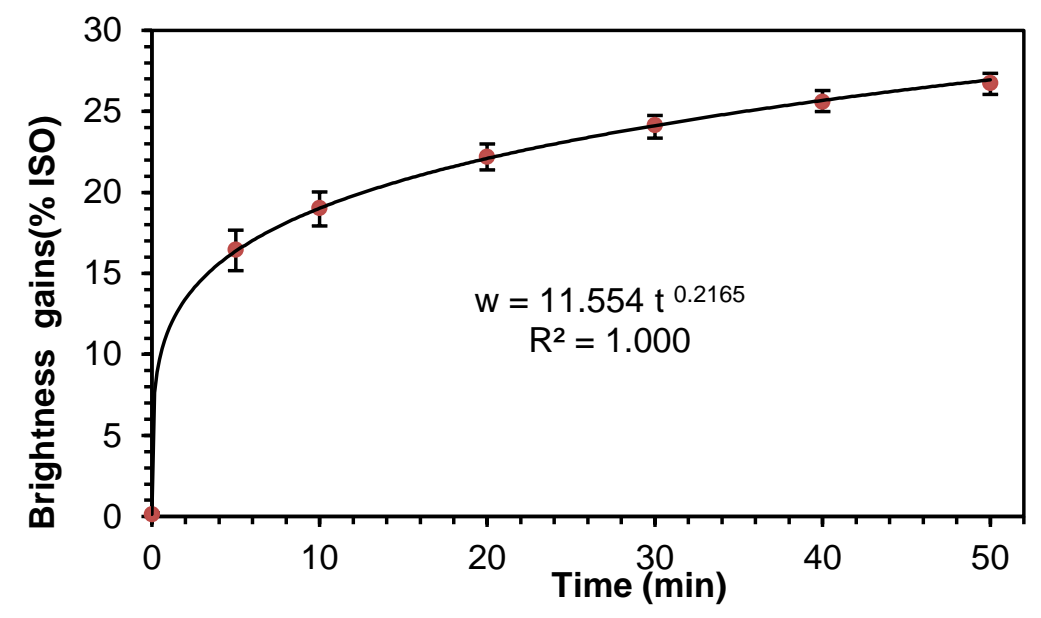

Fig. 2. Relationship between the brightness gain and bleaching reaction time

Figure 2 shows the relationship between bleaching reaction time and brightness gains during the CCS bleaching process. The relationship can be expressed in Eq. 4,

$$
w=11.554 t^{-0.2165}
$$

where $w$ is the brightness gain (\% ISO) and $t$ is the bleaching reaction time (min).

Rearranging and integrating both sides of Eq. 2, gives the rate equation in a suitable form for analysis of the experimental data as shown in Eq. 5,

$$
\ln (\mathrm{d} w / \mathrm{d} t)=\ln k+\gamma \ln w
$$

where $w$ is the observed brightness gain (\% ISO) and can be plotted against the bleaching reaction time, $\gamma$ is the reaction order, and $k$ is the rate constant. The reaction rate order $(\gamma)$ in Eq. 5 (i.e., the slope of the fitted curve in Fig. 3) was solved graphically. Therefore, the kinetic model in the CCS bleaching process can be expressed as Eq. 6,

$$
\mathrm{d} w / \mathrm{d} t=k w^{-3.619}
$$

where $w$ is the brightness gain (\% ISO) and $t$ is the bleaching reaction time (min). 


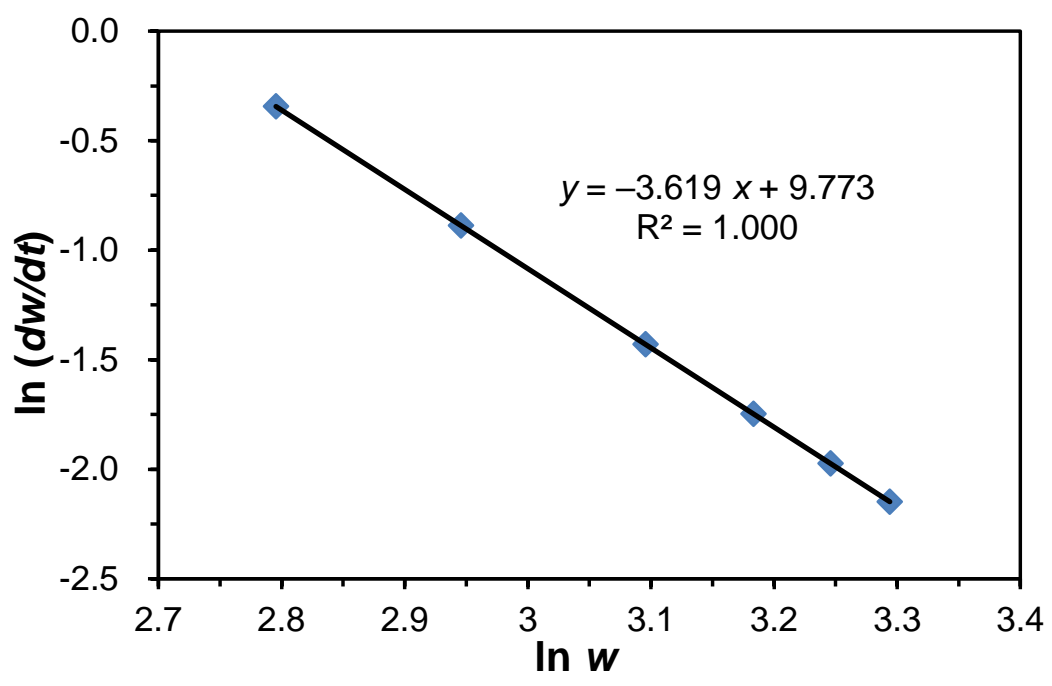

Fig. 3. The relationship between $\ln (\mathrm{d} w / \mathrm{d} t)$ and $\ln w$

It was found from Eq. 6 that the reaction order $(\gamma)$ was -3.619 , which was similar to Chen et al.'s result of $\gamma=-3.876$ (Chen et al. 1996), as the kinetic model was applied to the peroxide bleaching of kenaf. This result implied that the peroxide bleaching reactions were complex. The diversity of chromophoric groups in the pulp and penetrating difficultly of bleaching agents into the pulp fiber cells may have been the main reasons behind the complex reactions.

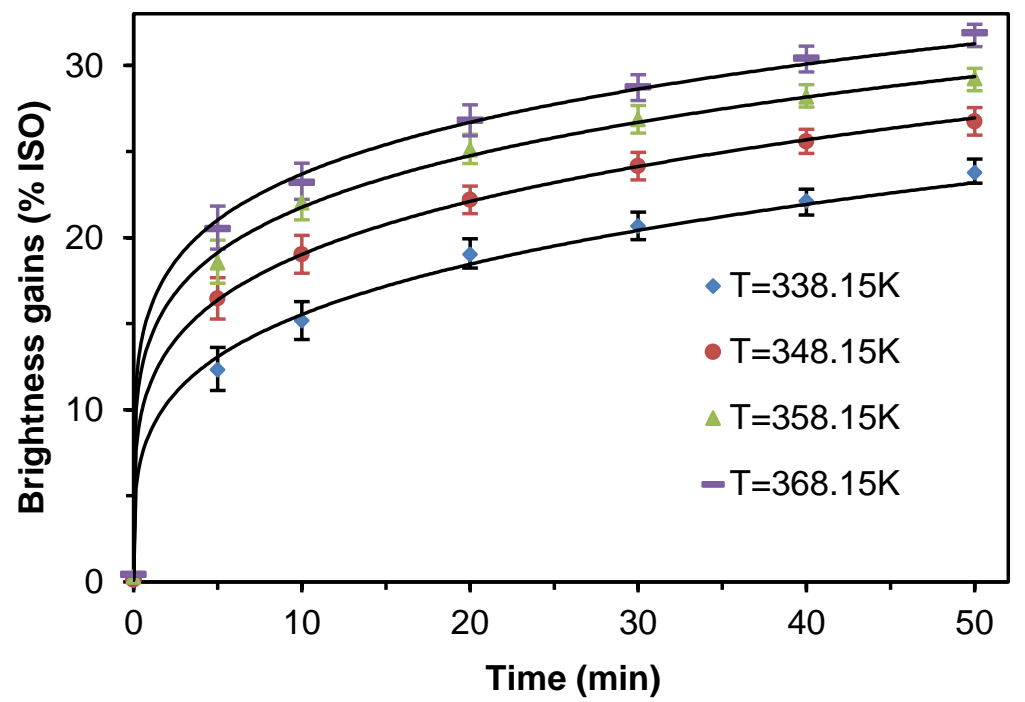

Fig. 4. Relationship between brightness gains and bleaching reaction time at different temperatures

\section{Effect of Bleaching Reaction Temperature and Determination of Activation Energy}

Figure 4 displays the time-dependent change in the brightness during the CCS bleaching process at $338.2 \mathrm{~K}, 348.2 \mathrm{~K}, 358.2 \mathrm{~K}$, and $368.2 \mathrm{~K}$. As expected, the brightness gains increased as the temperature increased. According to the Arrhenius equation as shown in Eq. 1, the logarithmic form of the activation energy can be expressed as Eq. 7, 


$$
\ln k=\ln A-\frac{\varepsilon}{R T}
$$

Depending on the rate constant $k$ in different temperature, one can make a chart of $\ln k-1 / T$, and then calculate activation energy $(\varepsilon)$ and pre-exponential factor $(A)$ by the slope and intercept of the straight line (Liu et al. 2014) shown in Fig. 5. The final Arrhenius equation can be expressed as Eq. 8,

$$
\ln k=109.84-\frac{288770}{R T}
$$

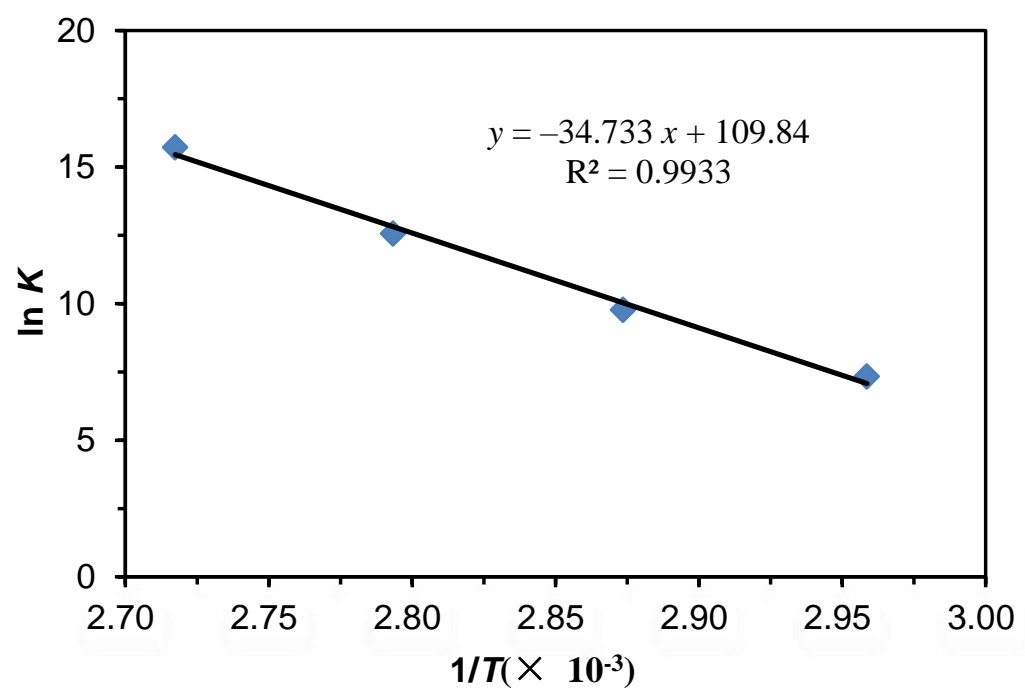

Fig. 5. Arrhenius plot of the bleaching reaction rate constant

In most peroxide bleaching processes, the value of activation energy is relatively lower. Wang et al. (2008) studied the kinetic model of the magnesium hydroxide-based peroxide bleaching process of spruce CTMP. The reported value of activation energy was $68 \mathrm{~kJ} / \mathrm{mol}$. Keating et al. (2008) explored the kinetics of hydrogen peroxide bleaching of western red cedar CTMP and reported the activation energy value ranging from $33 \mathrm{~kJ} / \mathrm{mol}$ to $72 \mathrm{~kJ} / \mathrm{mol}$, depending on different tree species and resultant pulp types. Compared to the activation energy values mentioned above, the activation energy value in the CCS bleaching process was relatively higher $(\varepsilon=288.77 \mathrm{~kJ} / \mathrm{mol})$ although the poplar CTMP has better bleachability than softwood (such as spruce and red cedar) CTMP. One of the possible reasons was that the concentrations of bleaching chemicals were maintained at a lower level (Sun et al. 2017), and therefore more energy was required to activate the bleaching reaction. 


\section{Confirmation of the Model}

An experimental run was conducted to confirm the established model. According to the present kinetic model, the trend of the brightness of poplar CTMP in the CCS bleaching process can be predicted. Figure 6 shows the results of the brightness gains predicted based on Eq. 6 versus those determined experimentally. The bleaching conditions were $0.2 \% \mathrm{Mg}(\mathrm{OH})_{2}, 0.3 \%$ stabilizer $\mathrm{P}$, and $0.2 \%$ DTPA on the oven-dried unbleached pulp. Approximately, $4.50 \mathrm{~g} / \mathrm{L} \mathrm{H}_{2} \mathrm{O}_{2}, 0.50 \mathrm{~g} / \mathrm{L} \mathrm{NaOH}$, and $2.50 \mathrm{~g} / \mathrm{L} \mathrm{Na}_{2} \mathrm{SiO}_{3}$ of the initial chemical concentrations in the bleaching system were used, where the bleaching reaction temperature was $353.15 \mathrm{~K}$. The results indicated that the developed rate equation accurately predicted the brightness gains in the CCS bleaching process for poplar CTMP.

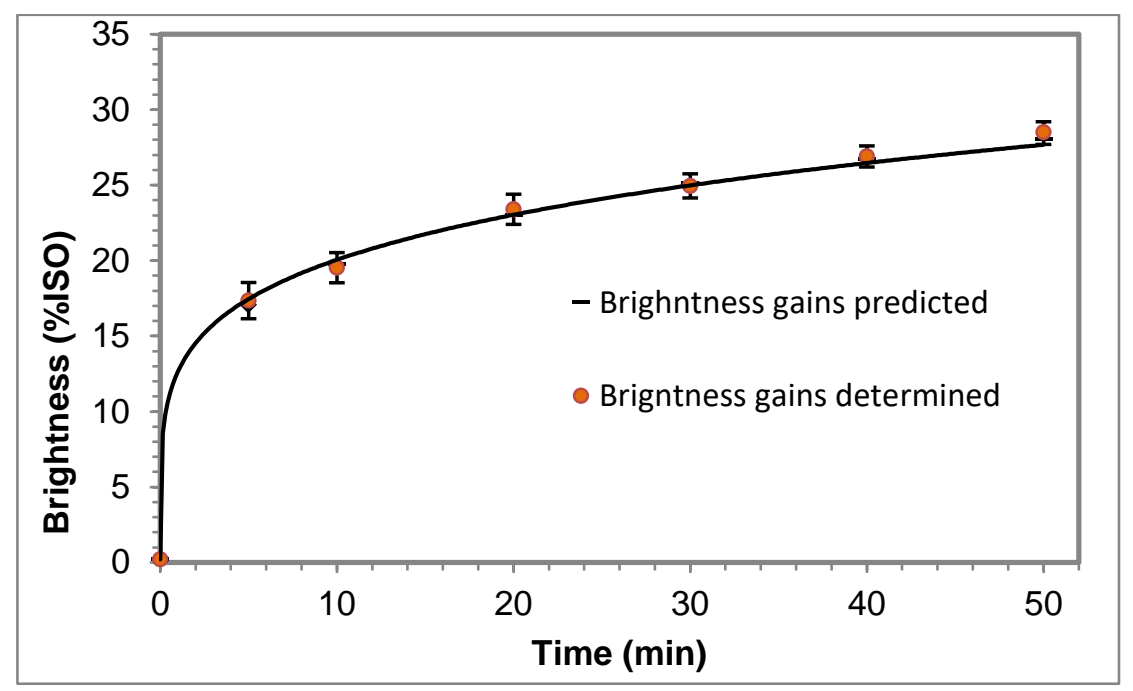

Fig. 6. Comparison of experimentally determined brightness gains with predicted ones

\section{CONCLUSIONS}

In this study, the kinetic model of the CCS peroxide bleaching process for poplar CTMP was developed based on the rate of brightness gains. One can conclude the following:

1. The brightness gains rapidly increased in the initial phase and slowly increased in the mid-to-late phase, and the reaction order, $\gamma=-3.62$, was obtained.

2. The Arrhenius' activation energy value was evaluated as $288.8 \mathrm{~kJ} / \mathrm{mol}$. The higher value was attributed to the lower chemical concentrations in the CCS bleaching system.

3. The developed kinetic model can well predict the experimental results.

\section{REFERENCES CITED}

Behrooz, R., Ghasemi, S., Atoii, G. A., and Fatehi, P. (2012). " $\mathrm{Mg}(\mathrm{OH})_{2}$-based hydrogen peroxide bleaching of CMP pulps at high consistency," BioResources 7(1), 161-172. DOI: 10.15376/biores.7.1.161-172 
Chen, B., Chen, Z., and Chen, M. (1996). "The kinetics of hydrogen peroxide bleaching of kenaf woody core SCMP," China Pulp and Paper 15(2), 23-26.

Ek, M., Gellerstedt, G., and Henriksson, G. (2009). "Pulping chemistry and technology," in: Pulp and Paper Chemistry and Technology, Series 2, KTH-Royal Institute of Technology, Stockholm, Sweden, pp. 313-320.

Keating, J., Johansson, I., John N., Saddler, J., and Beatson, R. (2008). "Kinetics of hydrogen peroxide brightening of western red cedar (Thuja plicata Donn) CTMP," Journal of Wood Chemistry and Technology 28(2), 153-166, DOI: 10.1080/02773810802125107

Liu, Y., Liu, Y. X., Wang, Z., and Peng, J. (2014). “Alkaline hydrolysis kinetics modeling of bagasse pentosan dissolution," BioResources 9(1), 445-454. DOI: 10.15376/biores.9.1.445-454

Shen, K. (2008). High-brightness Bleaching of China Fir CTMP Pulp and its Mechanism, Ph.D. Dissertation, Chinese Academy of Forestry, Beijing, China, pp. 5-6

Sun, X., Hou, Q., Zhang, B., and Zhao, G. (2017). "Improving the efficiency of hydrogen peroxide bleaching of chemimechanical pulp by continuous replenishment of bleaching chemicals," TAPPI Journal 16(6), 331-339.

Sundholm, J. (1999). "Mechanical pulping," in: Papermaking Science and Technology, Series 5, J. Gullichsen and H. Paulapuro (eds.), Finnish Paper Engineers' Association and TAPPI, Helsinki, Finland, pp. 11-12.

Wang, H., He, Z., and Ni, Y. (2008). "A kinetic model of the magnesium hydroxidebased peroxide bleaching process of a TMP," Journal of Wood Chemistry and Technology 28(1), 55-65. DOI: 10.1080/02773810801916514

$\mathrm{Xu}$, E. (2002). " $\mathrm{H}_{2} \mathrm{O}_{2}$ bleaching of mechanical pulps. Part IV: $\mathrm{H}_{2} \mathrm{O}_{2}$ consumption," Journal of Pulp and Paper Science 28(11), 379-383.

$\mathrm{Xu}$, E. C., and Hoddenhagh, M. (2003). "Alkaline peroxide bleaching of aspen chips. Part I: Kinetics mechanism and thermodynamics," Journal of Pulp and Paper Science 29(5), 155-158.

Zhao, Q. (2009). Research on Reinforced Hydrogen Peroxide Bleaching of Poplar CMP and Bleaching Mechanism, Ph.D. Dissertation, Beijing Forestry University, Beijing, China.

Zhao, Q., Pu, J., Mao, S., and Qi, G. (2010). "Process optimization of tetra acetyl ethylene diamine activated hydrogen peroxide bleaching of Populus nigra CTMP," BioResources 5(1), 276-290. DOI: 10.15376/biores.5.1.276-290

Article submitted: January 8, 2018; Peer review completed: May 13, 2018; Revised version received and accepted: May 21, 2018; Published: May 25, 2018.

DOI: 10.15376/biores.13.3.5408-5415 